\title{
TdT expression in Merkel cell carcinoma: potential diagnostic pitfall with blastic hematological malignancies and expanded immunohistochemical analysis
}

\author{
Monalisa Sur, Hosam AlArdati, Cathy Ross and Salem Alowami \\ Division of Anatomical Pathology, Department of Pathology and Molecular Medicine, McMaster University, \\ Hamilton, ON, Canada
}

\begin{abstract}
Merkel cell carcinoma is an uncommon aggressive primary cutaneous neuroendocrine carcinoma. Histologically, the differential diagnosis includes the 'small round cell' tumor group, particularly metastatic small cell carcinoma and blastic hematological malignancies involving skin/soft tissues. Terminal deoxynucleotidyl transferase (TdT) is a DNA polymerase, which is a sensitive and specific antibody for acute lymphoblastic lymphoma with a small proportion of acute myeloid leukemia showing positivity. This study investigates the expression of TdT in $\mathbf{2 0}$ cases with initial diagnosis of Merkel cell carcinoma. Archival blocks and slides were retrieved and reviewed and clinical information obtained from patient charts. Immunohistochemistry was performed and graded as: $\mathbf{0}$, no staining; $\mathbf{1}$, less than $\mathbf{5 0 \%}$ staining in the cells; $\mathbf{2}+, \mathbf{5 0} \%$ or more staining in the cells. After review, 15 cases were confirmed as Merkel cell carcinoma. Immunohistochemical positivity was as follows: $8 / 15$ cases were positive for TdT with strong nuclear staining, morphologically resembling 'blasts', AE1AE3, CAM5.2 (15/15) (both membrane and paranuclear dot positivity), CD56 and BCL-2 (15/15), Synaptophysin (13/15), Chromogranin A (11/15), NSE (15/15), CK20 (14/15), CK7 (3/15), both CK7 and CK20 (3/ 15), CD117 (8/15), CD99 (2/15), CD10 (1/15). One case was negative for CK7/CK20. All 15 cases were negative for thyroid transcription factor-1, LCA, CD20, CD3 and CD34. Expanded immunohistochemical panel with positive staining for epithelial/neuroendocrine markers, CK20, negative staining for hematolymphoid markers and awareness of TdT expression and other markers that show overlap with blastic hematological malignancies avoids misinterpretation in the diagnosis of Merkel cell carcinoma. This aids in further diagnosis of Merkel cell carcinoma, avoiding the potential diagnostic pitfall with other small round cell tumors and hematological malignancies primary or metastatic to the skin.

Modern Pathology (2007) 20, 1113-1120; doi:10.1038/modpathol.3800936; published online 21 September 2007
\end{abstract}

Keywords: TdT; merkel cell; carcinoma; hematological; malignancies; cutaneous

Merkel cell carcinoma is a rare, primary neuroendocrine carcinoma of the skin occurring on sunexposed areas in elderly patients. ${ }^{1}$ It accounts for less than $1 \%$ of all cutaneous malignancies, ${ }^{2}$ with approximately $53 \%$ occurring in the head and neck region and $35 \%$ present in the extremities. ${ }^{3}$ Merkel cell carcinoma may display aggressive biological behavior and can grow rapidly, metastasizing to the

Correspondence: Dr M Sur, MD, MRCPath (U.K.), FCPath (S.A.), FRCP(C), Department of Anatomical Pathology, Henderson General Hospital, 711 Concession Street, Hamilton, ON, Canada L8V 1 C3.

E-mail: surm@hhsc.ca

Presented at the 96th Annual meeting of the USCAP held in San Diego, CA from March 24-30, 2007.

Received 29 April 2007; revised 29 May 2007; accepted 5 June 2007; published online 21 September 2007 regional lymph nodes and other organs such as liver, bones, lungs and brain. Histologically, the differential diagnosis of Merkel cell carcinoma includes the 'small round cell' tumor group, particularly metastatic small cell carcinoma from other organs and hematological malignancies involving skin/soft tissues, which may include acute lymphoblastic lymphoma, acute myeloid leukemia and cutaneous natural killer (NK)/T-cell lymphoma and hematodermic CD56 + /CD4 + neoplasm. Terminal deoxynucleotidyl transferase (TdT) is an intranuclear enzyme, a template independent DNA polymerase expressed in approximately $90 \%$ of acute lymphoblastic lymphoma, in a small subset of acute myeloid leukemia and hematodermic CD56+l $\mathrm{CD} 4+$ neoplasm and a significant number of pediatric small round cell tumors. ${ }^{4,5}$ This study investigates the 
expression of TdT in Merkel cell carcinoma by immunohistochemistry along with an expanded immunohistochemical profile which aids in further diagnosis of Merkel cell carcinoma, avoiding potential diagnostic pitfall with other small round cell tumors presenting in cutaneous/soft tissue locations.

\section{Methods}

Twenty cases with initial diagnosis of Merkel cell carcinoma were retrieved from the institute database and archival blocks and slides were retrieved spanning 1999-2006. The pathology material was reviewed by two hematopathologists and a dermatopathologist. Immunohistochemistry was performed by using Standard Labeled Strep Avidin Biotin technique and graded as: 0 , no staining; $1+$, less than $50 \%$ staining in the cells; $2+, 50 \%$ or more staining in the cells. Detailed immunohistochemical panel performed is listed in Table 1. This panel was used to diagnose and differentiate Merkel cell carcinoma from other small cell neuroendocrine carcinomas metastasizing to the skin. This panel was also used to distinguish a subset of Merkel cell carcinomas which can morphologically resemble 'blastic' hematological malignancies and can be confused with hematological malignancies such as acute lymphoblastic lymphoma, acute myeloid leukemia, NK//T-cell lymphoma, hematodermic CD56 + /CD4 + neoplasm that can present in the skin and soft tissue locations. Clinical information was obtained from patient charts and is listed in Table 2.

\section{Results}

After review, 15 cases were confirmed as Merkel cell carcinoma. Five cases that excluded from the study were diagnosed on review as follows: basaloid squamous cell carcinoma; B-cell non-Hodgkin's lymphoma; metastatic small cell carcinoma (three cases). There were 5 men and 10 women with age range from 54-86 years; mean age 70 years. In our series, $60 \%$ of the tumors were present in the extremities, $26 \%$ in the head and neck region and $13 \%$ in the trunk. Two cases also showed metastasis to left inguinal lymph node and liver respectively, at the time of cutaneous presentation. At the time of this study, eight patients (four men and 4 women) were dead and seven patients were still alive (one men and six women).

\section{Microscopy}

Nine cases demonstrated morphology similar to conventional small cell carcinoma (Figure 1a and b). Six cases showed morphology resembling highgrade hematological malignancies. The cells were large to intermediate in size with vesicular nuclei, open chromatin pattern and 1-3 nucleoli. The background exhibited a starry sky appearance with brisk mitotic activity (Figure $2 \mathrm{a}$ and $\mathrm{b}$ ).

Table 1 Immunohistochemical panel

\begin{tabular}{|c|c|c|c|c|}
\hline Antibody & Manufacturer & Dilution & Antigen retrieval & Clone \\
\hline AE1/AE3 & Dakocytomation & $1 / 100$ & Protease & AE1 AE3 \\
\hline Cam 5.2 & Beckton Dickenson & $1 / 100$ & Protease & Cam 5.2 \\
\hline CK7 & Dakocytomation & $1 / 50$ & Protease & OV-TL 12/30 \\
\hline CK20 & Dakocytomation & $1 / 100$ & Protease & Ks 20.8 \\
\hline Chromogranin A (CGA) & Dakocytomation & $1 / 100$ & $\begin{array}{l}\text { HIER } \\
\text { Citrate-6 buffer }\end{array}$ & DAK-A3 \\
\hline Synaptophysin (SYN) & Dakocytomation & $1 / 100$ & $\begin{array}{l}\text { HIER } \\
\text { Citrate-6 buffer }\end{array}$ & Polyclonal \\
\hline NSE & Dakocytomation & $1 / 2000$ & $\begin{array}{l}\text { HIER } \\
\text { Citrate-6 buffer }\end{array}$ & BBS/NC/V1-H14 \\
\hline CD56 & Novocastra & $1 / 50$ & $\begin{array}{l}\text { HIER } \\
\text { DAKO buffer }\end{array}$ & $1 \mathrm{~B} 6$ \\
\hline CD45 (LCA) & Dakocytomation & $1 / 200$ & None & 2B11/PD7126 \\
\hline CD10 & Novocastra & $1 / 25$ & $\begin{array}{l}\text { HIER } \\
\text { Citrate-6 buffer }\end{array}$ & $56 \mathrm{C} 6$ \\
\hline CD34 & Novocastra & $1 / 50$ & None & QBEnd/10 \\
\hline TTF-1 (thyroid transcription factor-1) & Dakocytomation & $1 / 200$ & $\begin{array}{l}\text { HIER } \\
\text { EDTA-8 buffer }\end{array}$ & $8 G 7 G 3 / 1$ \\
\hline TdT & Novocastra & $1 / 25$ & $\begin{array}{l}\text { HIER } \\
\text { DAKO buffer }\end{array}$ & SEN 28 \\
\hline CD99 & Dakocytomation & $1 / 100$ & $\begin{array}{l}\text { HIER } \\
\text { EDTA-8 buffer }\end{array}$ & $12 \mathrm{E} 7$ \\
\hline BCL-2 & Dakocytomation & $1 / 25$ & $\begin{array}{l}\text { HIER } \\
\text { Citrate-6 buffer }\end{array}$ & 124 \\
\hline CD117 & Dakocytomation & $1 / 400$ & $\begin{array}{l}\text { HIER } \\
\text { Citrate-6 buffer }\end{array}$ & Polyclonal \\
\hline CD 3 & Cell margue & $1 / 1500$ & $\begin{array}{l}\text { HIER } \\
\text { Citrate-6 buffer }\end{array}$ & Polyclonal \\
\hline CD20 & Dakocytomation & $1 / 1000$ & None & L26 \\
\hline
\end{tabular}


Table 2 Patient characteristics

\begin{tabular}{|c|c|c|c|c|}
\hline Case & Age & Sex & Site & Survival \\
\hline 1 & 72 & $\mathrm{~F}$ & Right elbow & Alive \\
\hline 2 & 85 & $\mathrm{M}$ & Nose & Dead \\
\hline 3 & 74 & $\mathrm{M}$ & Neck & Dead \\
\hline 4 & 79 & $\mathrm{~F}$ & Left abdominal wall with left groin lymph node metastasis & Dead \\
\hline 5 & 54 & $\mathrm{~F}$ & Right arm & Alive \\
\hline 6 & 67 & $\mathrm{~F}$ & Left thigh & Alive \\
\hline 7 & 79 & $\mathrm{~F}$ & Right thigh & Alive \\
\hline 8 & 73 & $\mathrm{M}$ & Left thigh & Dead \\
\hline 9 & 86 & $\mathrm{~F}$ & Left calf & Dead \\
\hline 10 & 82 & $\mathrm{~F}$ & Left thigh & Alive \\
\hline 11 & 78 & $\mathrm{M}$ & Left chest wall with liver metastasis & Dead \\
\hline 12 & 80 & $\mathrm{~F}$ & Right calf & Dead \\
\hline 13 & 62 & $\mathrm{~F}$ & Left arm & Alive \\
\hline 14 & 74 & $\mathrm{M}$ & Right ear & Alive \\
\hline 15 & 83 & $\mathrm{~F}$ & Right eyelid & Dead \\
\hline
\end{tabular}
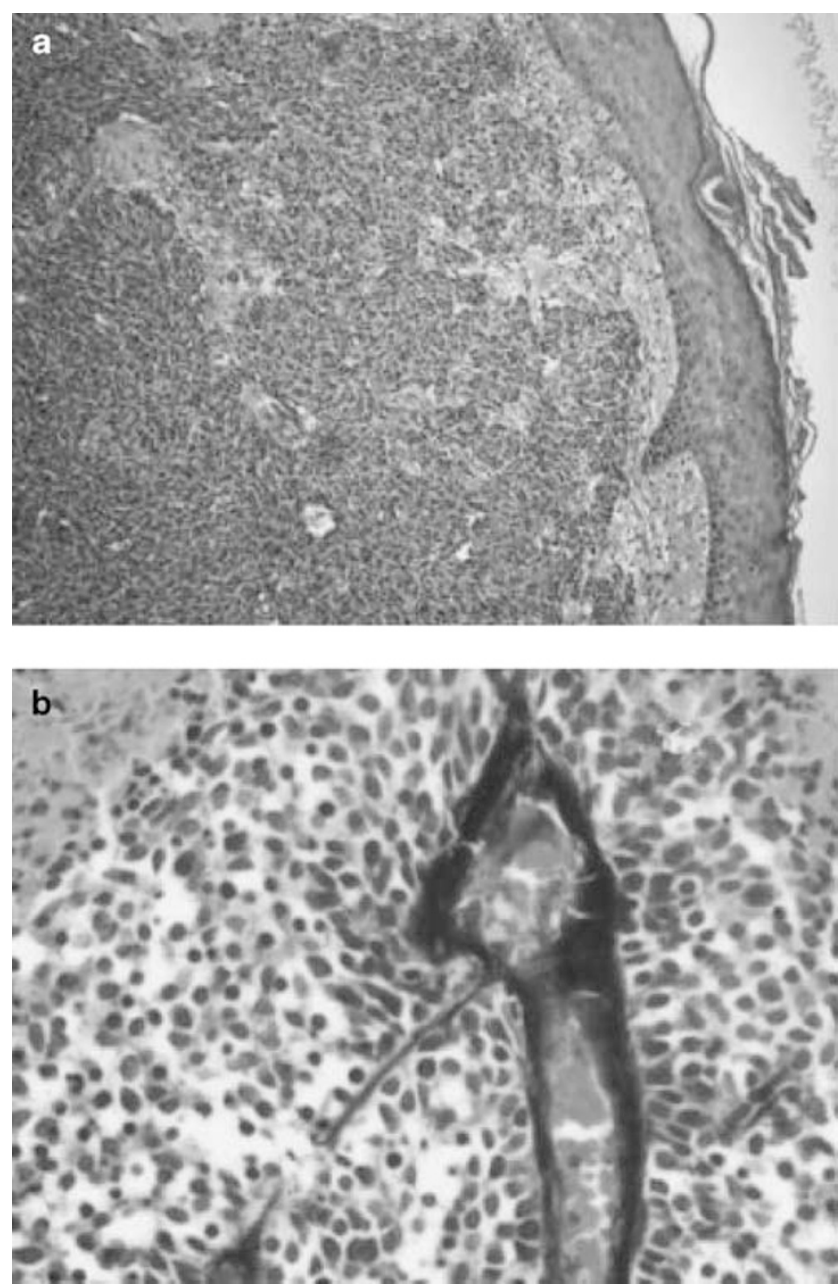

Figure 1 (a) Conventional Merkel cell carcinoma showing features of a small cell carcinoma $(\mathrm{H} \& \mathrm{E})(\times 100)$. (b) Merkel cell carcinoma showing small cells with high nuclear/cytoplasmic ratio, hyperchromatic nuclei and a blood vessel showing Azzopardi effect $(\mathrm{H} \& \mathrm{E})(\times 400)$.

\section{Immunohistochemistry}

The immunohistochemical staining pattern in the neoplastic cells is shown in Table 3. Eight out of 15
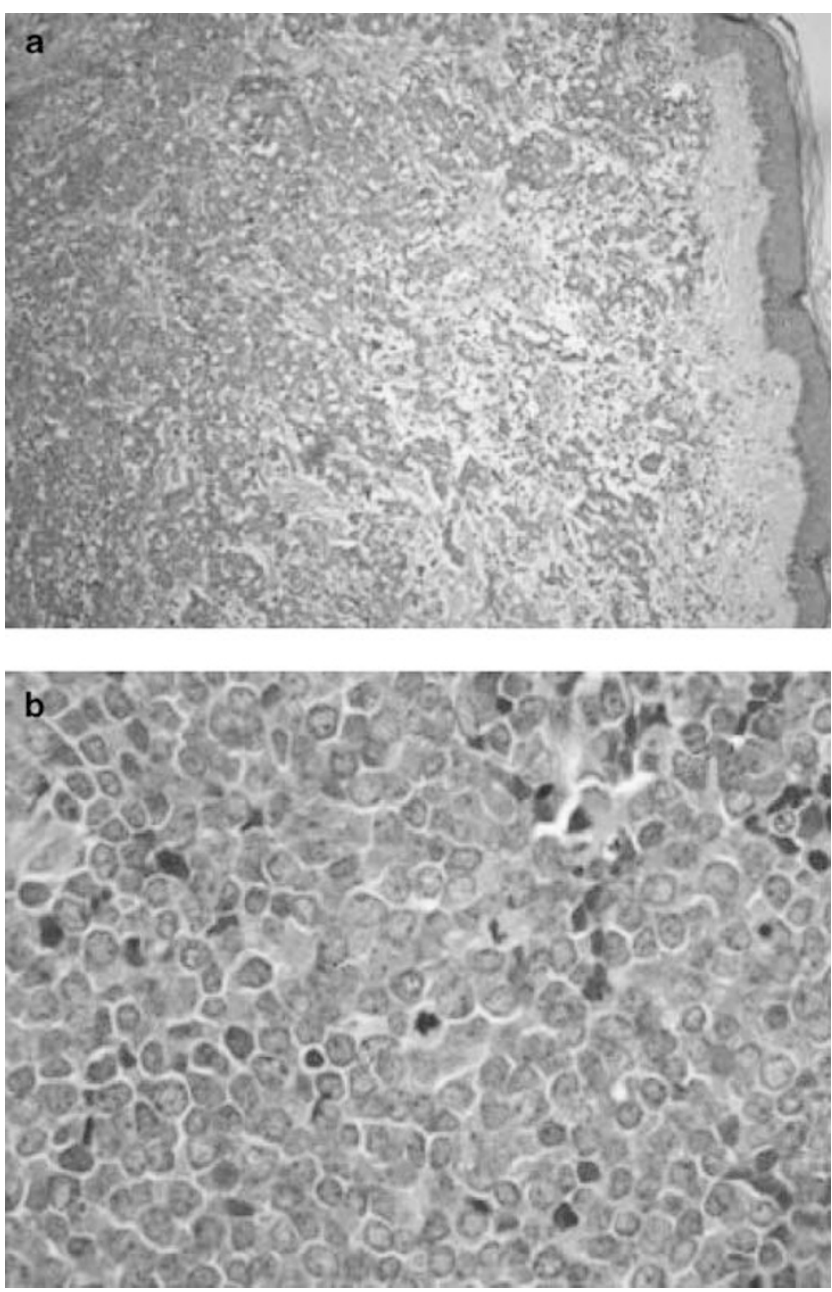

Figure 2 (a) Merkel cell carcinoma resembling 'blastic' hematological malignancy $(H \& E)(\times 100)$. (b) High-power view showing large to intermediate cells with vesicular nuclei, 1-3 nucleoli and brisk mitosis $(\mathrm{H} \& \mathrm{E})(\times 400)$.

cases were positive for TdT with 6 cases showing $2+$ (Figure 3a and b), and 2 cases showing $1+$ nuclear staining. Six of the eight cases expressing 
Table 3 Immunohistochemical profile

\begin{tabular}{|c|c|c|c|c|c|c|c|c|c|c|c|c|c|c|c|}
\hline Immunohistochemical stains & 1 & 2 & 3 & 4 & 5 & 6 & 7 & 8 & 9 & 10 & 11 & 12 & 13 & 14 & 15 \\
\hline $\mathrm{TdT}$ & - & - & - & - & - & + & ++ & ++ & - & ++ & ++ & - & ++ & ++ & + \\
\hline CD117 & - & - & - & ++ & - & - & ++ & - & ++ & ++ & ++ & ++ & ++ & ++ & - \\
\hline CD99 & - & - & - & - & - & - & - & + & ++ & - & - & - & - & - & - \\
\hline TTF-1 & - & - & - & - & - & - & - & - & - & - & - & - & - & - & - \\
\hline CD56 & ++ & ++ & ++ & ++ & ++ & ++ & ++ & ++ & ++ & ++ & ++ & ++ & ++ & ++ & ++ \\
\hline CD10 & - & - & - & - & ++ & - & - & - & - & - & - & - & - & - & - \\
\hline CD34 & - & - & - & - & - & - & - & - & - & - & - & - & - & - & - \\
\hline BCL-2 & ++ & ++ & ++ & ++ & + & ++ & ++ & ++ & ++ & ++ & ++ & ++ & ++ & ++ & ++ \\
\hline AE1AE3 & ++ & + & ++ & ++ & ++ & ++ & ++ & ++ & ++ & ++ & ++ & ++ & ++ & + & ++ \\
\hline Cam5.2 & ++ & + & ++ & ++ & ++ & ++ & ++ & + & ++ & ++ & ++ & + & ++ & ++ & ++ \\
\hline CK 7 & - & - & - & ++ & & - & + & - & - & ++ & + & - & - & - & - \\
\hline CK 20 & ++ & ++ & + & ++ & + & ++ & ++ & - & ++ & ++ & + & ++ & ++ & + & ++ \\
\hline Synaptophysin (SYN) & ++ & - & ++ & ++ & ++ & ++ & ++ & - & ++ & ++ & ++ & ++ & ++ & ++ & ++ \\
\hline Chromogranin (CGA) & ++ & ++ & ++ & - & ++ & ++ & - & ++ & - & ++ & ++ & - & ++ & ++ & ++ \\
\hline NSE & ++ & ++ & ++ & ++ & ++ & ++ & ++ & ++ & ++ & ++ & ++ & ++ & ++ & ++ & ++ \\
\hline CD45 (LCA) & - & - & - & - & - & - & - & - & - & - & - & - & - & - & - \\
\hline CD20 & - & - & - & - & - & - & - & - & - & - & - & - & - & - & _- \\
\hline CD3 & - & - & - & - & - & - & - & - & - & - & - & - & - & - & - \\
\hline
\end{tabular}

+, less than $50 \%$ cells staining; ++, $50 \%$ or more cells staining.
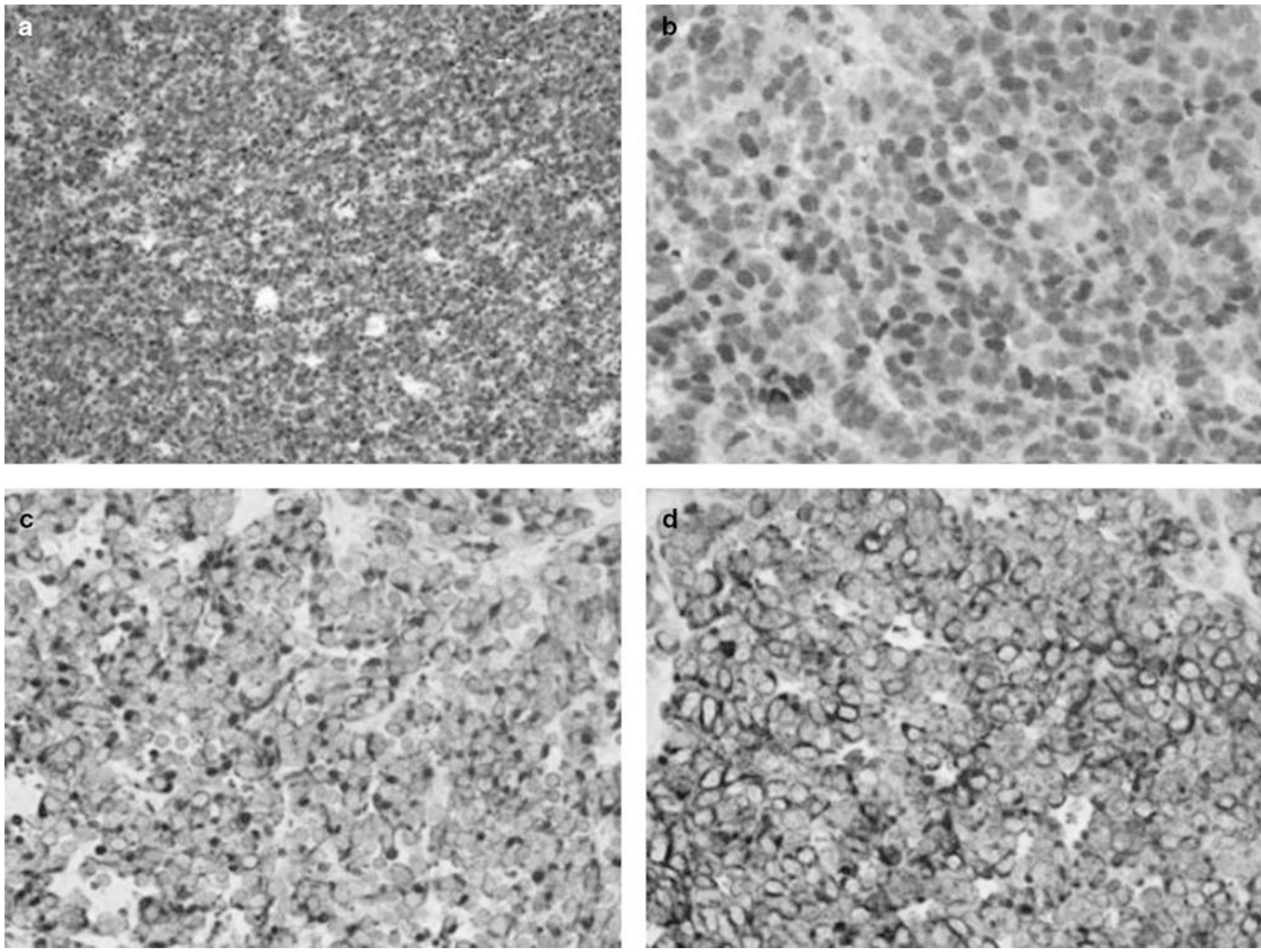

Figure 3 (a, b) $2+$ nuclear staining for TdT (a) $(\times 100)$, (b) $(\times 400)$. (c, d) $2+$ membrane and paranuclear dot staining for CAM5.2 (c), CK20 (d) $(\times 400)$.

TdT morphologically resembled blastic hematological malignancies. All the cases showed positive staining for CAM5.2 (Figure 3c) and AE1AE3.
Fourteen cases were positive for CK20 (Figure 3d) with three cases demonstrating positivity for both CK7 (Figure 4a) and CK20. One case was negative 

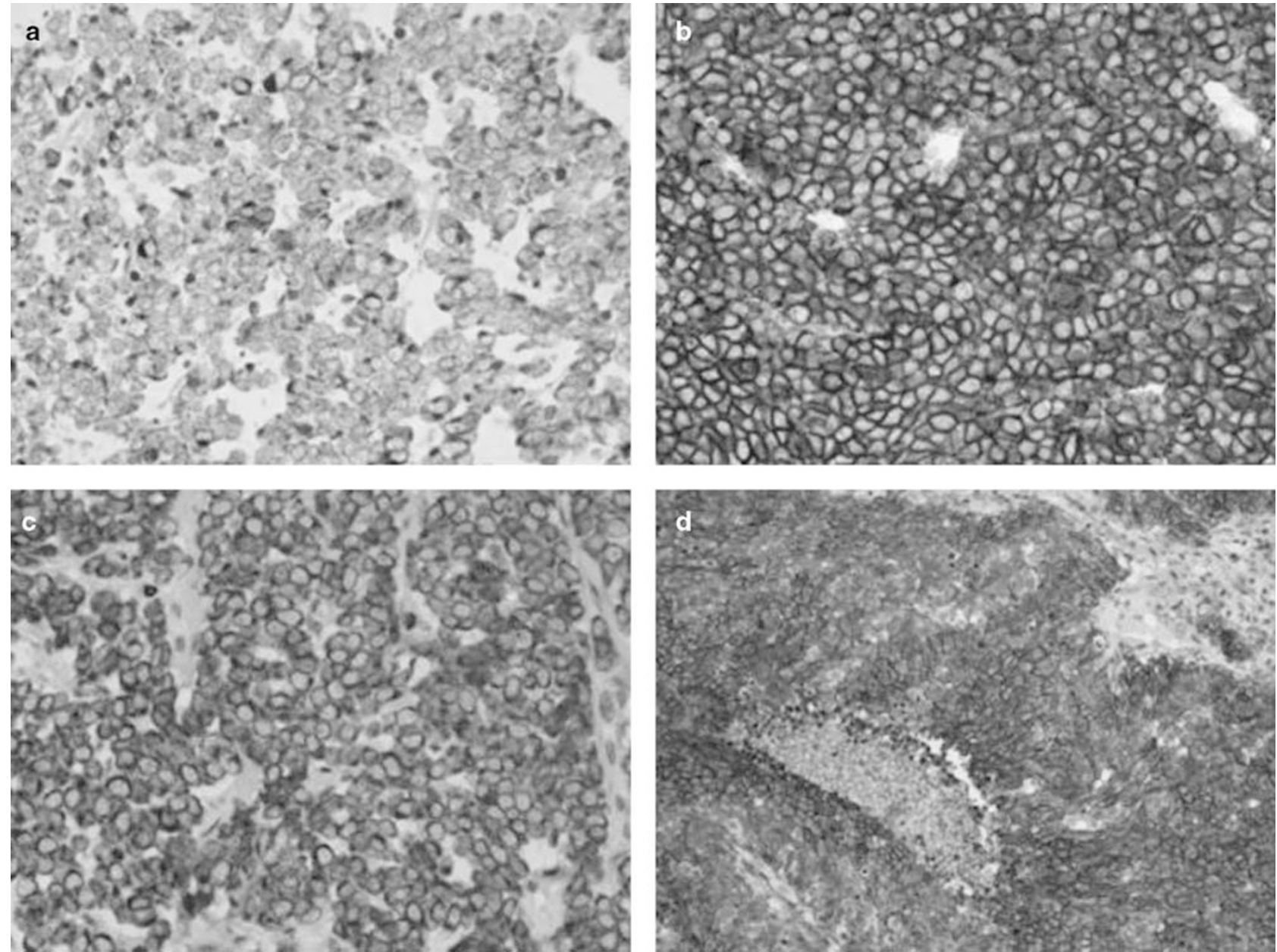

Figure $42+$ staining for CK7 (a), CD56 (b), Bcl-2 (c), CD117 (d) $(\times 400)$.

for both CK20 and CK7. The staining pattern for all epithelial markers were both membranous and paranuclear dot type. All our cases showed $2+$ positivity for two or more neuroendocrine markers (NSE, CGA and Synaptophysin). CD56 and BCL2 demonstrated $2+$ membrane positivity in all the cases (Figure 4b and c). Eight cases showed 2+ membrane staining for CD117 (Figure 4d), two cases demonstrated $1+$ membrane staining for CD99 and one case showed $2+$ membrane staining for CD10. Ki-67 showed a proliferative index of $70-85 \%$ in all the cases. All 15 cases were negative for thyroid transcription factor-1 (TTF-1), LCA, CD20, CD3 and CD34.

\section{Discussion}

Merkel cell carcinoma is a primary cutaneous neuroendocrine carcinoma found in sun-exposed areas of elderly individuals (mean age in our study being 70 years). ${ }^{1}$ Only $5 \%$ of all reported cases were below the age of 50 years, 54 years being the youngest in our series. There is a slight male preponderance in one series, ${ }^{6}$ with a predilection for female preponderance in another series. ${ }^{7}$ Our series also showed a female preponderance. In our study, patients who died were more males than females; this finding is similar to previous studies showing male gender to be an adverse prognostic factor. $^{8,9}$ Although, head and neck is the most common location, ${ }^{3}$ the extremities $(60 \%)$, followed by head and neck $(26.6 \%)$, and trunk $(13.3 \%)$ were the preferred sites in our study.

Merkel cell carcinoma shares many histological and immunohistochemical features with small cell neuroendocrine carcinoma from other locations. ${ }^{1}$ Although, CK20 has been reported to be occasionally positive in small cell carcinoma of the lung, ${ }^{10}$ it is considered to be a fairly specific and sensitive marker for Merkel cell carcinoma showing membrane and paranuclear dot positivity in the neoplastic cells, ${ }^{11,12}$ a finding further corroborated in this study. In addition, three cases $(20 \%)$ were also positive for CK7 and CK20, the pattern of staining for CK7 being similar to CK20. Although, one case was negative for both CK7 and CK20, all the cases demonstrated positivity for epithelial markers CAM5.2 and AE1AE3 and two or more neuroendocrine markers. The case that was negative for both 
CK7 and CK20 did not clinically have any other lesion elsewhere. TTF-1 is a nuclear transcription protein, which is expressed in pulmonary and extrapulmonary small cell carcinomas, but not in Merkel cell carcinoma. ${ }^{13}$ All our cases were consistently negative for TTF-1, making this an important marker to differentiate Merkel cell carcinoma from cutaneous metastasis of small cell carcinoma from other sites, particularly in the setting of CK7 positivity or in the absence of staining for CK20 and/or CK7.

$\mathrm{TdT}$ is an intranuclear enzyme, a templateindependent DNA polymerase that catalyzes the repetitive addition of deoxyribonucleotides to the $3^{\prime}$-OH-terminated segment of DNA without the need for a template strand. ${ }^{4}$ The gene responsible for expression of TdT has been found to span at least $65 \mathrm{~kb}$ and is located to chromosome $10 \mathrm{q} 23-\mathrm{q} 25 .{ }^{14}$ TdT is expressed in most cases of acute lymphoblastic lymphoma, a small subset of acute myeloid leukemia, occasional cases of CD56 + /CD4 + hematodermic neoplasm and some pediatric non-hematopoietic small round cell solid tumors. ${ }^{4,5}$ In this study, $53 \%(8 / 15)$ of the cases expressed strong diffuse nuclear staining for TdT. Six of these cases morphologically resembled blastic hematological malignancies with large- to intermediate-sized cells showing vesicular nuclei and one or two prominent nucleoli. This morphology could lead to an erroneous diagnosis of a blastic hematological malignancy in the skin, given the TdT positivity. To the best of our knowledge, this is the first series to identify TdT expression in Merkel cell carcinoma by immunohistochemistry, which was published as an abstract in the Modern Pathology issue of March 2007, following presentation at the 96th USCAP meeting in San Diego. ${ }^{15}$ Since then, a recent correspondence has been published where the authors have found similar nuclear immunoreactivity in 10 out of their 28 cases of Merkel cell carcinoma $(36 \%){ }^{16}$

The embryological origin of merkel cells remains controversial. Merkel cells are generally believed to originate from neural crest-derived cells of the amine precursor uptake and decarboxylation system, and a residual epidermal stem cell. Some investigators have suggested that neoplastic cells in Merkel cell carcinoma arise from stem cells that develop neuroendocrine properties similar to the wild-type merkel cells. ${ }^{17}$ Recent evidence has suggested that merkel cells are derived from epidermal keratinocytes. ${ }^{18} \mathrm{TdT}$ is normally expressed in thymocytes and precursors of lymphocytes in the bone marrow, but not in mature lymphocytes. Most investigators support the concept that both medullary and cortical epithelia arise from a common precursor and, in the early stage of thymus ontogeny, the epithelia coexpress markers that later segregate into cortical (cytokeratin 8 positive) and medullary (cytokeratin 5 positive) epithelial compartments. This differentiation is thought to occur under the influence of the mesenchymal cells that migrate from the neural crest to the thymic components. ${ }^{19,20}$ There is a great deal of similarity and parallelism between the ontogenic development of the thymic cells and the merkel cells of the skin. It is possible that this positive immunoreactivity in our series is an aberrant expression of TdT by the mutant merkel cells. The functional significance of this rare biological event is not very clear. TdT is known to catalyze and promote the addition of deoxynucleotides to the 3'-OH-terminal (amino terminal end) of DNA and functions without the need for a DNA template. It is possible that this enzyme may help DNA repair in damaged neoplastic cells or apoptotic cells which are found in significant numbers in Merkel cell carcinoma, and in this manner may prolong the survival of the tumor cells, augmenting their malignant behavior. It would be interesting to further study the nature and mechanism of this expression of TdT in Merkel cell carcinoma by actual chemical extraction, isolation and purification of the coding DNA, its amplification by polymerase chain reaction and its characterization by DNA sequencing. Cytogenetic anomalies occur in 30-47 \% of Merkel cell carcinomas. The most frequent change is the loss of heterozygosity due to deletions or translocations on chromosome 1. Molecular studies on neoplastic cells in Merkel cell carcinoma have indicated the involvement of two tumor suppressor genes-p73, a member of the TP53 family of tumor suppressors localized on chromosome 1, and succinate-ubiquinone oxidoreductase subunit D, localized on chromosome $11 .^{21,22}$ The multiplicity of chromosomal changes in Merkel cell carcinoma may be a reflection of the highly malignant nature of the neoplasm and possibly ongoing somatic mutations during the progressive evolution of its aggressive malignant nature. The significance of the cytogenetic and molecular changes in the induction of TdT expression by this tumor remains conjectural. The presence of multiple chromosomal changes, which include chromosome 10 , may have some relevance to the activation of the gene that codes for TdT protein in Merkel cell carcinoma. $^{23}$

CD56 (neural cell adhesion molecule) is positive in neoplastic plasma cells, leukemias with myelomonocytic differentiation, CD56 + /CD4 + hematodermic neoplasm, NK/T-cell lymphomas, myogenic tumors and tumors showing neuroendocrine differentiation. ${ }^{24-26}$ In our series, CD56 was positive in all the cases, indicating that CD56 is a sensitive but not a specific marker for Merkel cell carcinoma and needs to be interpreted in conjunction with other markers and not in isolation in the diagnosis of Merkel cell carcinoma. This is of importance because CD56 is positive in Merkel cell carcinomas and hematological malignancies such as CD56+l CD4 + hematodermic neoplasm, NK/T-cell lymphoma and myeloid leukemia with myelomonocytic differentiation, which can morphologically resem- 
ble Merkel cell carcinoma showing blast-like histology in the cutaneous and soft tissue location.

CD99 showed $1+$ positivity in two cases. CD99, a MIC2 gene product and a p30/32 cell surface glycoprotein demonstrates positive staining in a wide variety of small round blue cell tumors, which include Ewing's sarcoma/PNETs family, acute lymphoblastic lymphoma, acute myeloid leukemia, alveolar rhabdomyosarcoma, mesenchymal chondrosarcoma. ${ }^{27}$ Epithelial tumors expressing CD99 include neuroendocrine tumors such as islet cell tumors, carcinoid tumors and pulmonary small cell carcinomas. ${ }^{28,29}$ The immunoreactivity for CD99 in Merkel cell carcinoma should be taken into consideration when differential diagnosis with other small round blue cell tumors is considered.

CD117(C-KIT) showed $2+$ membrane staining in eight cases $(53 \%)$. CD117 is also a marker of acute myeloid leukemia, which can morphologically mimic Merkel cell carcinoma showing blast-like cells in the cutaneous location. A number of papers have been published on CD117 positivity in Merkel cell carcinoma. ${ }^{30,31}$ The presence of CD117 positivity in Merkel cell carcinoma possibly indicates a $c$-kit mutation with a constitutive activation of this receptor tyrosine kinase. However, no correlation could be established with survival in these patients and its clinical significance is still unknown. Further, prospective studies are required to assess whether this finding could have an impact on the treatment protocol.

One of our cases was positive for CD10. The exact significance of CD10 expression in Merkel cell carcinoma is not known and may be an aberrant expression. All our cases showed strong diffuse $2+$ membrane positivity for BCL-2. Expression of BCL-2 protein is frequent in Merkel cell carcinoma, but positive immunoreactivity and recurrences and survival are unrelated. ${ }^{32,33}$

In general, Merkel cell carcinoma resembles a typical small cell neuroendocrine carcinoma, with cohesive sheets of small cells with scant cytoplasm, powdery dispersed chromatin, irregular nested groups of infiltrating cells and azzopardi effect. In our series, interestingly, 6 of the 15 cases also exhibited a more diffuse discohesive pattern of infiltration with a starry sky appearance at low power. The neoplastic cells were medium- to largesized with brisk mitotic activity, with no appreciable cytoplasm and vesicular nuclei with one to three nucleoli resembling blastic hematological malignancies. TdT was expressed in $53 \%$ of our cases, which is an unusual finding. In addition, Merkel cell carcinoma expressing TdT can show similar morphologic features as blastic hematological malignancies, which can be a potential diagnostic pitfall with other hematological malignancies expressing TdT. In our series, Merkel cell carcinoma was also positive for CD117 (53\%), CD56 and BCL2 (100\%), CD99 (13\%) and CD10 (6.6\%); markers that are also expressed in hematological malignancies described above. Therefore, we recommend that when faced with a cutaneous or soft tissue lesion showing blastic morphology, the immunohistochemical panel should include epithelial markers (AE1AE3, CAM5.2, CK7 and CK20), neuroendocrine markers (NSE, Synaptophysin and CGA) and CD56, TTF-1 and first line hematolymphoid markers (LCA, CD34, TdT, CD10, CD3, CD20, myeloperoxidase and CD117). CD34 is a hematopoietic progenitor marker, which is positive in most cases of acute lymphoblastic lymphoma along with TdT and CD10 and some cases of acute myeloid leukemia but negative in Merkel cell carcinoma. CD99 positivity in Merkel cell carcinoma should be interpreted in conjunction with other markers for small round cell tumors. CD56 and BCL2 are sensitive but not specific markers and can be used in conjunction with epithelial markers, CK20 and neuroendocrine markers in the diagnosis of Merkel cell carcinoma. Although CK7 was positive in $20 \%$ of our cases, TTF-1 was negative in all our cases, making this an important marker to differentiate Merkel cell carcinoma from cutaneous metastasis of small cell carcinoma from other sites.

In conclusion, awareness of the positive staining pattern for the less commonly used markers in the diagnosis of Merkel cell carcinoma and markers which can show overlap with hematological malignancies avoids misinterpretation and erroneous diagnosis with other tumors, which may morphologically mimic Merkel cell carcinoma.

\section{References}

1 Skelton HG, Smith KJ, Hitchcock CL, et al. Merkel cell carcinoma. Analysis of clinical, histologic, and immunohistologic features of 132 cases with relation to survival. J Am Acad Dermatol 1997;37:734-739.

2 Miller RW, Rabkin CS. Merkel cell carcinoma and melanoma. Etiological similarities and differences. Cancer Epidemiol Biomarker Prev 1999;8:153-158.

3 Tai PT, Yu E, Tonita J, et al. Merkel cell carcinoma of the skin. J Cutan Med Surg 2000;4:186-195.

4 Chilosi M, Pizzolo G. Review of terminal deoxynucleotidyl transferase. Biologic aspects, methods of detection, and selected diagnostic applications. Appl Immunohistochem 1995;3:209-221.

5 Mathewson RC, Kjelsberg CR, Perkins SL. Detection of terminal deoxynucleotidyl transferase in non-hematopoietic small round cell tumors of children. Pediatr Pathol Lab Med 1997;17:835-844.

6 Agelli M, Clegg LX. Epidemiology of primary Merkel cell carcinoma in the United States. J Am Acad Dematol 2003;49:832-841.

7 Koljonen V, Bohling T, Granhroth G, et al. Merkel cell carcinoma: a clinicopathological study of 34 patients. Eur J Surg Oncol 2003;29:607-610.

8 Hitchcock CL, Bland KI, Laney III RG, et al. Neuroendocrine ( Merkel cell) carcinoma of the skin. Its natural history, diagnosis, and treatment. Ann Surg 1998;207: 201-207.

9 Shaw JH, Rumball E. Merkel cell tumor: clinical behavior and treatment. Br J Surg 1991;78:138-142. 
10 Bobos M, Hytiroglou P, Kostopoulos I, et al. Immunohistochemical distinction between Merkel cell carcinoma and small cell carcinoma of the lung. Am J Dermatopathol 2006;28:99-104.

11 Chan JK, Suster S, Wenig BM, et al. Cytokeratin 20 immunoreactivity distinguishes Merkel cell (primary cutaneous neuroendocrine) carcinoma and salivary gland small cell carcinoma from small cell carcinomas of various sites. Am J Surg Pathol 1997;21:226-234.

12 Scott MP, Helm KF. Cytokeratin 20: a marker for diagnosing Merkel cell carcinoma. Am J Dermatopathol 1999;21:16-20.

13 Agoff SN, Lamps LW, Philip AT, et al. Thyroid Transcription Factor-1 is expressed in extra pulmonary small cell carcinomas but not in other extra pulmonary neuroendocrine tumors. Mod Pathol 2000;13:238-242.

14 Isobe M, Huebner K, Erikson J, et al. Chromosome localization of the gene for human terminal deoxynucleotidyl transferase to region 10q23-q25. Proc Natl Acad Sci USA 1985;82:5836-5840.

15 Sur M, Al Ardati H, Ross C, et al. TdT expression in Merkel cell carcinoma: potential diagnostic pitfall with blastic hematological malignancies and expanded immunohistochemical analysis. Modern Pathol 2007;20(Suppl 2):99A.

16 Bernd H-W, Krokowski M, Feller AC, et al. Expression of terminal desoxynucleotidyl transferase in Merkel cell carcinoma. Histopathology 2007;50:676-678.

17 Hoefler H, Denk H, Lackinger E, et al. Immunocytochemical demonstration of intermediate filament cytoskeleton proteins in human endocrine tissues and (neuro)-endocrine tumors. Virchows Arch A Pathol Anat Histopathol 1986;409:609-626.

18 Narisawa Y, Hashimoto K, Nihei Y, et al. Biological significance of dermal Merkel cells in development of cutaneous nerves in human fetal skin. J Histochem Cytochem 1992;40:65-71.

19 Klug DB, Carter C, Drouch E, et al. Interdependence of cortical thymic epithelial cell differentiation on Tlineage commitment. Proc Natl Acad Sci USA 1998;95:11822-11827.

20 Bockman DE, Kirby ML. Dependence of thymic development on derivatives of neural crest. Science 1984;223:498-500.

21 Van Gele M, Kaghad M, Leonard JH, et al. Mutation analysis of P73 and TP 53 in Merkel cell carcinoma. Br J Cancer 2000;82:823-826.
22 Yienpruksawan A, Coit DG, Thaler HT, et al. Merkel cell carcinoma. Prognosis and management. Arch Surg 1991;126:1514-1519.

23 Van Gele M, Spelman F, Vandessompele JO, et al. Characteristic pattern of chromosomal gains and losses in Merkel cell carcinoma detected by comparative genomic hybridization. Cancer Res 1998;58: 1503-1508.

24 Kontogianni K, Nicholson AG, Butcher D, et al. CD56: a useful tool for the diagnosis of small cell lung carcinomas on biopsies with extensive crush artifact. J Clin Pathol 2005;58:978-980.

25 McNiff JM, Cowper SE, Lazova R, et al. CD56 staining in Merkel cell carcinoma and natural killer-cell lymphoma: magic bullet, diagnostic pitfall, or both? J Cutan Pathol 2005;32:541-545.

26 Martin JM, Nicolau MJ, Galan A, et al. CD4+/CD56+ hematodermic neoplasm: a precursor hematological neoplasm that frequently first presents in the skin. J Eur Acad Dermatol Venereol 2006;20:1129-1132.

27 Ramani P, Rampling D, Link M. Immunocytochemical study of twelve, E7 in small round cell tumors of childhood: an assessment of its sensitivity and specificity. Histopathology 1993;23:557-561.

28 Lumadue JA, Askin FB, Perlman EJ. MIC 2 analysis of small cell carcinoma. Am J Clin Pathol 1994;102: 692-694.

29 Llombart B, Monteagudo C, Lopez- Guerrero JA, et al. Clinicopathological and immunohistochemical analysis of 20 cases of Merkel cell carcinoma in search of prognostic markers. Histopathology 2005;46: 622-634.

$30 \mathrm{Su}$ LD, Fullen DR, Lowe L, et al. CD 117 (KIT receptor) expression in Merkel cell carcinoma. Am J Dermatopathol 2002;24:289-293.

31 Strong S, Shalders K, Carr R, et al. KIT receptor (CD117) expression in Merkel cell carcinoma. Br J Dermatol 2004;150:384-385.

32 Kennedy MM, Blessing K, King G, et al. Expression of bcl-2 and p53 in Merkel cell carcinoma. An Immunohistochemical study. Am J Dermatopathol 1996;18: 273-277.

33 Feinmesser M, Halpern M, Fenig E, et al. Expression if the apoptosis- related oncogenes bcl- 2, bax, p53 in Merkel cell carcinoma: can they predict treatment response and clinical outcome? Hum Pathol 1999;30: 1367-1372. 